\title{
SPRING 2008 - A DEVASTATING TIME FOR MOUNTAIN BLUEBIRDS ON THE PRAIRIES
}

LOIS M. JOHNSON, Box 555, Provost, AB TOB 3S0, E-mail: <lomjo@telusplanet.net>.

The 2008 bluebird season started out as a normal year. The bird houses were clean, the fronts were all in place and the weather was balmy. Hundreds of Mountain Bluebirds returned to their natal area to establish nesting territories. Normally they return to this district around Provost, Alberta between March 5th and 10th. This year was no exception. Shirt sleeve weather by April 16th had encouraged mated pairs to chose nest boxes and proceed with nest building. Egg laying would not start for about two weeks. All seemed to be proceeding normally.

But then, snow arrived! Not just a few flakes for a short period of time, but about $30 \mathrm{~cm}$ accompanied by strong winds, blizzard conditions and colder than normal temperatures. The intense storm lasted from April 19 to 27 with disastrous effects on many birds and animals. The bluebirds were no exception. Though these hardy birds generally experience one or more snowstorms each spring, the conditions this time were too severe and the duration too long.

Deep snow cover prevented foraging for food; spiders, bugs, even cocoons or larva could not be found. After their long migration from Texas, body reserves were already low. Bluebirds will huddle together (often up to a dozen in one nest box) to keep warm during cold snaps and these did, but they could not cope with the extended low temperatures and strong winds. Many died from hypothermia and starvation.
I estimate that the bluebird population on the Johnson Bluebird Trail was reduced close to the numbers when we first started our hobby in 1970 (seven pair that first year.)

On April 27th I ventured out on a prime part of my trail and saw no live bluebirds only one dead bird that had huddled in a house.

May 20th, after driving close to $14 \mathrm{~km}$ on the trail, I found one pair in a tree near a nest box. Could this be the only ones that survived? Normally by this time most birds would be incubating eggs. There was no sign of eggs in the nest box.

As I checked the nest boxes on my 357 house trail over the 2008 summer and fall, many comparisons became evident.

- In 2008 Mountain Bluebirds occupied $5.8 \%$ of my houses; normally they occupy around $50 \%$.

- Tree Swallows occupied $76 \%$ of my houses in 2008, as compared to $55 \%$ normally.

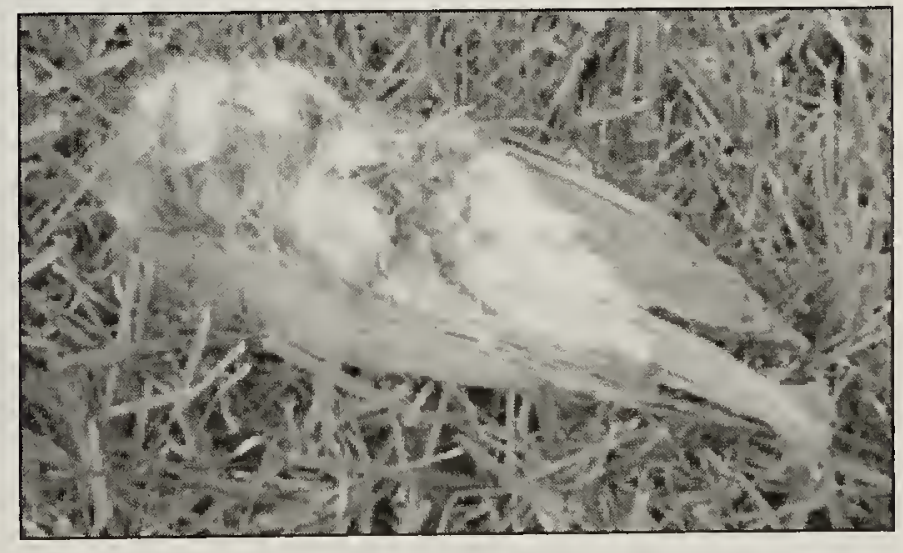

Figure 1. Male Mountain Bluebird missing tarsi and feet. Lois Johnson 
- House Wren numbers remained fairly constant.

- By June 6th, on a normal year, I can band hundreds of bluebird nestlings; this year my trail had no young birds ready for banding until June 18 th.

- The number of bluebirds fledging the nest in 2008 was 76 as compared to about $600-700$ on a normal year.

Other observations from 2008 bring forth more questions than answers.

Thirteen adult male bluebirds as compared to one adult female were found dead in nest boxes as a result of the severe weather. Do females return from migration with more body fat and are better equipped to survive the severe weather? Did the males not allow females in the birds houses when "the chips were down"? Did the females leave the area for a more favourable climate? (It seems most of Alberta was held in the grips of the storm.)

Of the 13 dead males found in nest boxes, nine had no feet or tarsi on their body (Figure 1). At first I suspected cannibalism as three birds were in a single box. Then a single bird in another box had met the same fate. Had the feet and legs frozen and fallen off? I shudder to think of the pain and struggling the birds endured while attempting to climb into the box using only the leg stumps.

During the nesting season, very few males were observed near the nest boxes. Did one or both parents travel several kilometres to find a mate? I suspect there were many "single mom" families. One group of healthy banded youngsters died in the nest when their mother (and sole food source) failed to return.

The greatest number of successful nests on my trail was near where a fire occurred around May 20th. This brush fire was after the April storm date. Did the bluebirds congregate there during or following the storm? Heat from the fire might bring out insects for the starving birds making it a choice place to stay and raise the young. Fourteen young birds fledged successfully along this 1.5 kilometre of trail.

And finally, how long will it take the bluebirds to return to their previous numbers?

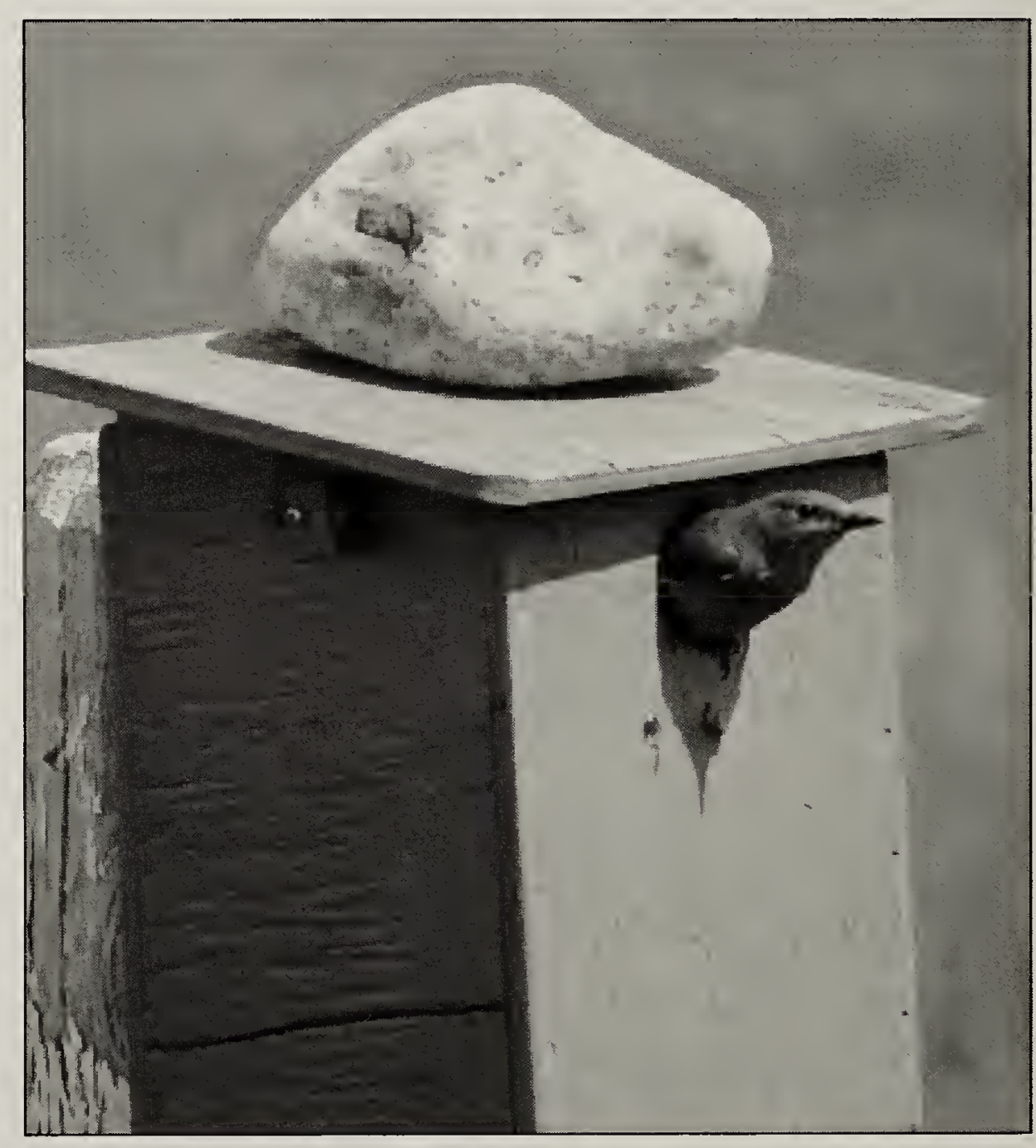

Mountain Bluebird

George Tosh 